\title{
AVALIAÇÃO DAS PROPRIEDADES MECÂNICAS DO CONCRETO PRODUZIDO COM RESÍDUO DE ISOLADORES ELÉTRICOS DE PORCELANA
}

\section{Evaluation of mechanic properties of concrete produced with residual porcelain electrical insulators}

\author{
Patrícia Mota Milhomem ${ }^{1}$, Jéssyca Mendes da Silva ${ }^{2}$, Patrick Silva Costa ${ }^{3}$
}

Recebido em 16 de fevereiro de 2017; aceito em 18 de julho de 2017; disponível on-line em 07 de novembro de 2017.

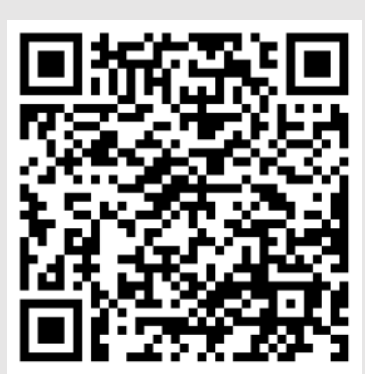

\section{PALAVRAS CHAVE:}

Isoladores de porcelana;

Reciclagem;

Concreto; Absorção

Resistência à compressão.

\section{KEYWORDS:}

Porcelain insulator;

Recycling;

Concrete; Absorption;

Compressive strength.

\section{* Contato com os autores:}

${ }^{1}$ e-mail: patriciamotamilhomem@gmail.com (P. M. Milhomem)

Engenheira Civil, mestranda, Programa de Pós-Graduação em Estruturas e Construção Civil - PECC da Universidade de Brasília UnB.

2e-mail: jejemsilva@gmail.com ( J.M. Silva )

Engenheira Civil e Agrícola, mestranda, Programa de Pós-Graduação em Engenharia Civil - PPGEC da Universidade Federal de Santa Catarina - UFSC (62-992402857).

${ }^{3}$ e-mail: patrick.silva.costa@gmail.com (P. S. Costa)

Engenheiro Civil, bacharel pela Universidade Federal do Pará - UFPA.
ABSTRACT: The search for new materials capable of partially replacing concrete components has leveraged research in a number of areas, particularly with regard to waste recycling (construction, industry and others). In this context, the use of porcelain electrical insulators has been studied as an effective possibility of replacing the small 作 the fine aggregate using a 1: 1: 43: 2.07: 0.4 (cement: aggregate coarse: fine aggregate: water). Through the physical characterization of the residue, the same was classified as (influence of the grinding process). Absorption (at 28 days), compressive strength and tensile were performed. The absorption test showed that the insulator, although having a higher absorption than the natural sand $10.56 \%$ and $0.34 \%$, ), did not interfere with the value of the slump test of concrete. The results of compressive strength showed a considerable improvement based on the data obtained, proving the effectiveness of the use of this material as partial replacement of the aggregates in the concrete composition. 


\section{INTRODUÇÃO}

A constante busca para uma eficaz utilização de resíduos sólidos como agregados alternativos, principalmente aqueles referentes a entulhos provenientes das construções e produção cerâmica, tem ganhado importância nos últimos anos. $\mathrm{O}$ objetivo desta procura por novos materiais seja no que se refere à substituição ou adição dos produtos do concreto (agregados) e do próprio cimento, é a redução dos impactos ambientais gerados na extração da matéria-prima, como também a devastação de imensas áreas de disposição dos recursos naturais.

Estudos na área de adição e substituição de componentes do concreto observam que a utilização de resíduos cerâmicos promove benefícios ao composto e podem ser adicionados com segurança, sem a necessidade de mudanças na produção e aplicação do processo. A porcentagem de substituição usualmente utilizada em estudos relacionados aos agregados comuns por resíduos cerâmicos varia entre $20 \%$ a 50\%, entretanto, há casos que se recomenda a substituição total dos agregados (FRANCK et al, 2004; CAMPOS, 2009).

Os isoladores de porcelana são materiais cerâmicos classificados como cerâmica branca por terem em sua estrutura um corpo de massa recoberto por uma camada vítrea de esmalte constituída, basicamente, por argila. Possuem elevado ponto de fusão e são manufaturadas a frio em formas plásticas para que seja realizado o processo de queima, geralmente, a $2.000{ }^{\circ} \mathrm{C}$ (CAMPOS, 2011).

De acordo com Campos (2011), este material varia sua composição química conforme sua utilização sendo que os mais comuns são chamados de isoladores de quartzo, compostos por, aproximadamente $30 \%$ de caulim e argila, $30 \%$ de feldspato e $40 \%$ de quartzo. Cabe ressaltar que esses teores podem mudar dependendo das condições elétricas e dielétricas, mecânicas e térmicas exigidas.

O isolador elétrico é um dispositivo utilizado para garantir o isolamento de fios ou cabos energizados, com seus pontos de sustentação adjacentes. Exige-se, portanto, que o isolador possua uma grande capacidade de se opor à passagem de corrente elétrica, além de elevada resistência mecânica para suportar também os distúrbios meteorológicos (SOUZA, NEVES e ALARCON, 2004).

Os isoladores atuam como suportes mecânicos para proteção de estruturas e equipamentos elétricos e eletrônicos, localizados em postes elétricos e subestações. Devem, portanto, suportar intempéries climáticas (desde que limitadas em projeto), ataque por contaminantes (ex. maresia e poluição) e fungos quando em elevada umidade, além de situações externas, como vandalismo (ISOLADORES SANTANA, 2017).

De acordo com a Resolução no 307 do Conselho Nacional do Meio Ambiente (CONAMA, 2002) - Brasil os rejeitos referentes aos isoladores elétricos de porcelana são classificados como resíduos de Classe $A$ e sua reutilização ou reciclagem na forma de agregados, ou encaminhados a áreas de aterro de resíduos da construção civil, sendo dispostos de modo a permitir a sua utilização ou reciclagem futura.

Outra possibilidade de reutilização da porcelana é em substituição ao cimento, uma vez que agrega vantagens econômicas, tais como a redução da produção de clínquer quando em substituição ao cimento (menor consumo de energia), redução das emissões de $\mathrm{CO}_{2}$, reutilização dos isoladores descartados na natureza, ganho de resistência à compressão quando dosado de maneira correta devido a atividade pozolânica proporcionada por esse material, aumento da resistência à ação da água pura e ácida, redução do calor de hidratação, aumento da impermeabilidade e redução dos tempos de início e fim de pega do concreto (Juan et al., 2010).

Campus e Paulon (2015) ao utilizar agregados alternativos de isoladores elétricos de porcelana em concretos encontraram, para resistência a compressão aos 7 dias, maiores valores de resistência à medida que aumenta o teor de porcelana incorporado (14\%) e aos 28 dias, um acréscimo de $18 \%$, com $100 \%$ de substituição. 
De acordo com os pesquisadores, essa melhoria baseia-se na melhoria da distribuição granulométrica desses agregados alternativos, conferindo melhor adensamento, ausência de material orgânico e baixa capacidade de absorção de água. Para resistência à tração por compressão diametral, os melhores valores foram encontrados quando ocorre a substituição de $75 \%$ do material aos sete dias, mas aos $28,100 \%$ de substituição conferiu resultados mais significativos, chegando a 73\% de aumento da resistência.

Avaliando os efeitos da reciclagem secundária de rejeitos de porcelanas elétricas em estruturas de concreto, Portella et al (2006), verificaram que sua incorporação aos concretos promoveu uma redução em torno de $5 \%$ do consumo de cimento (substituição de 50 e 100\%), sendo economicamente viáveis. Todos os valores de resistência após os 14 dias já encontravam-se acima do estipulado por norma, $25 \mathrm{MPa}$.

Entretanto, não existem muitas pesquisas consolidadas/publicadas a esse respeito, sendo de grande relevância a execução e publicação deste trabalho para que a reutilização de isoladores elétricos de porcelana seja implementada nas tecnologias já existentes em construtoras e concreteiras.

\section{OBJETIVO}

O objetivo deste estudo é avaliar a substituição parcial da areia por resíduo de isolador elétrico de porcelana nos teores de $25 \%$ e $50 \%$ após moagem no traço de concreto $1: 1,43$ : 2,07: 0,4 (cimento : agregado graúdo : agregado miúdo : água). A viabilidade da utilização dos isoladores neste processo se consolida, uma vez que, essas aplicações não estão sujeitas a exigências estruturais, e sua reutilização é importante para a sustentabilidade, como também, para a manutenção da certificação da ISO 14001 da empresa Dow Cornnig Silício do Brasil que forneceu o resíduo.

\section{MATERIAL E MÉTODOS}

\subsection{CIMENTOS E AGREGADOS}

No projeto experimental realizado em laboratório para produção do concreto utilizou-se o cimento Portland Composto CP || E-32, muito utilizado em obras de pequeno porte na região norte do Brasil.

Como agregado miúdo natural, foi utilizado o seixo lavado proveniente do leito do Rio Tocantins, que é adquirido e utilizado no município de Tucuruí pelas concreteiras. Já o agregado miúdo artificial (reciclado) é proveniente do resíduo de isoladores elétricos de porcelana da empresa Dow Corning Silício do Brasil, localizada no município de Breu Branco PA. No presente trabalho o resíduo do isolador elétrico de porcelana, será chamado de areia de Isoladores de Porcelana (AIP).

Depois de coletar o resíduo de porcelana, fez-se a quebra das peças em pedaços menores com o auxílio de um socador. Depois de quebrado, o resíduo apresentou formato lamelar e foi peneirado (Figura 1) para que fossem colocados em tamanhos praticamente uniformes na máquina de ensaio a abrasão Los Angeles (Figura 2). Realizou-se 180 voltas utilizando 8 esferas de ferro contendo $2 \mathrm{~kg}$ de resíduo buscando um resíduo AIP de granulometria uniforme. Devido a falta de recursos e equipamentos apropriados e, com base na experiência dos laboratoristas, padronizou-se a trituração dos isoladores na máquina de abrasão Los Angeles, segundo procedimento acima descrito.

No entanto, devido a características peculiares desse material, o mesmo apresentou boa resistência ao ensaio de abrasão, tornando-se a maior dificuldade da pesquisa. Sendo assim, houve-se a necessidade de realizar esse processo por diversas vezes a fim de obter a granulometria desejada. Após o processo de trituração, a AIP foi peneirada e separada em conformidade com sua granulometria (agregado graúdo, fino e fíller).

Cabe ressaltar, para a realização dos ensaios, a água potável utilizada foi proveniente da rede de abastecimento de Vila Permanente, fornecida pela Eletrobrás/Eletronorte, atendendo, portanto, os requisitos impostos pela norma NBR 6118 (ABNT, 2014). 


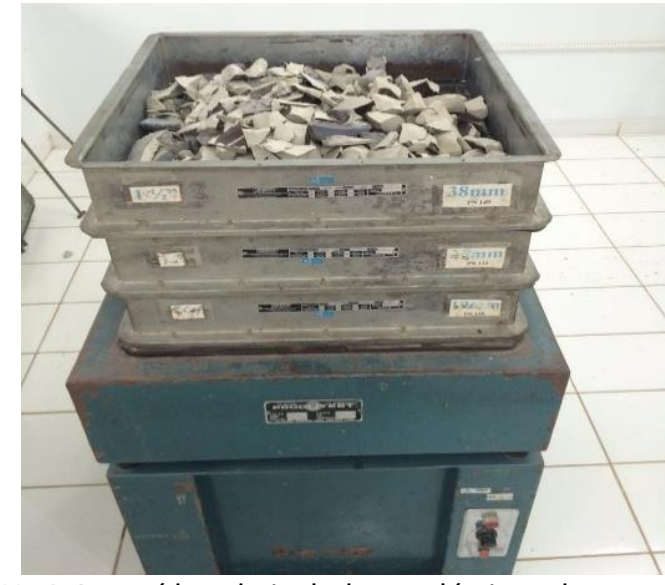

FIGURA 1: Resíduo de isoladores elétricos de porcelana depositados em peneiras.

FONTE: Autoria própria.

\subsection{PRODUÇÃO DOS CORPOS DE PROVA}

A produção dos corpos de prova foi baseada no traço de referência, sem adição de AIP, equivalente à $1: 1,43: 2,07: 0,4$. Os demais traços foram produzidos com teores de substituição da areia pelo resíduo equivalente a $25 \%$ e $50 \%$, em massa. Foram produzidos 33 corpos de prova de dimensão $10 \mathrm{~cm} \times 20 \mathrm{~cm}$ (Figura 3), seguindo as recomendações da NBR 5738 (ABNT, 2015). A produção dos corpos de prova foi destinada à realização dos ensaios de resistência à compressão, resistência à tração por compressão diametral e absorção por imersão.

\subsection{ENSAIO DE GRANULOMETRIA, ABSORÇÃO E MASSA ESPECÍFICA}

As amostras de AIP foram caracterizadas quanto à distribuição granulométrica com base no ensaio de peneiramento em conformidade com a norma NBR NM 248 (ABNT, 2003). O método utilizado para a determinação da absorção de água do agregado miúdo e do resíduo de porcelana pela

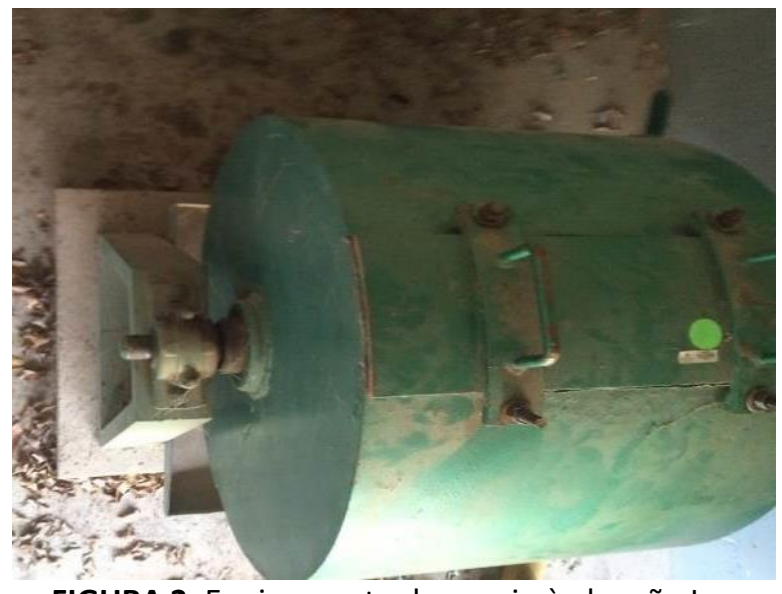

FIGURA 2: Equipamento de ensaio à abrasão Los Angeles utilizado no experimento.

FONTE: Autoria própria.

da NBR NM 30 (ABNT, 2001). Para a determinação da massa específica, seguiu-se as recomendações da NBR NM 52 (ABNT, 2009) como referência para realização dos ensaios. Para cada ensaio foram realizadas 03 repetições.

\subsection{ENSAIO DAS PROPRIEDADES TECNOLÓGICAS}

Para determinação das propriedades tecnológicas do concreto com substituição de parte dos agregados por AIP, realizou-se os seguintes ensaios:

- Determinação da consistência através do ensaio de abatimento de tronco de cone conforme a NBR NM 67 (ABNT, 1998) (Figura 4);

- Resistência à compressão axial aos 07 e 28 dias para cada traço obtido, com e sem adição (Figura 5);

- Resistência à tração por compressão diametral aos 07 e 28 dias;

- Absorção de água por imersão dos corpos de prova aos 28 dias;

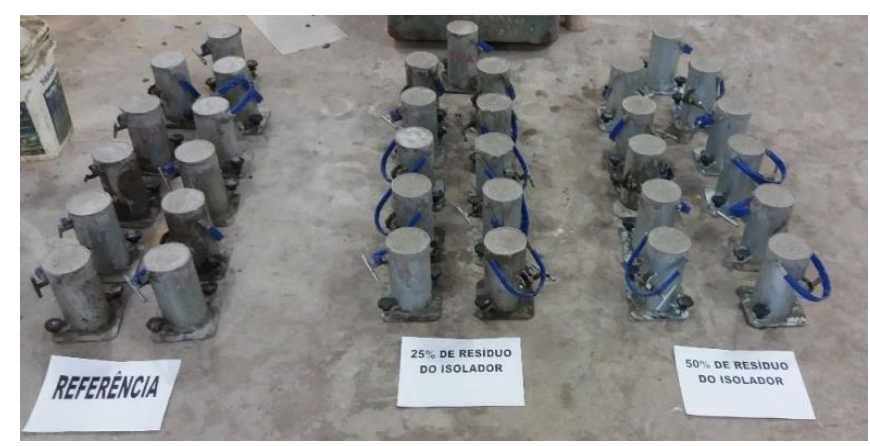

FIGURA 3: Corpos de prova produzidos.

FONTE: Autoria própria. 


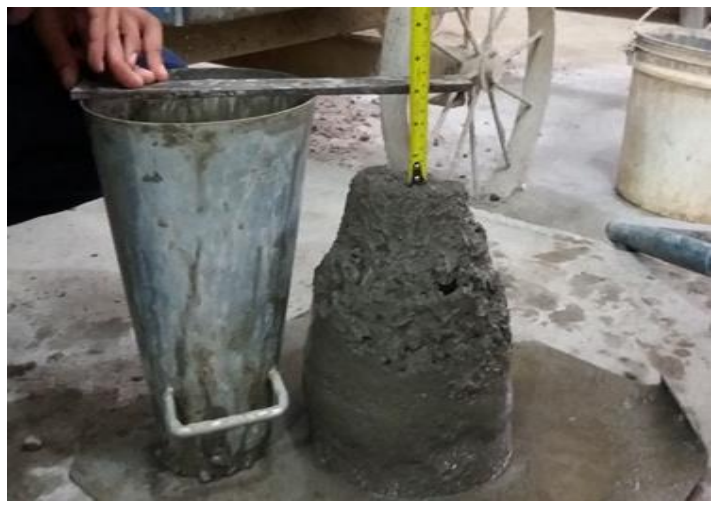

FIGURA 4: Ensaio de abatimento de tronco de cone

(Slump Test).

FONTE: Autoria própria.

\section{RESULTADOS E DISCUSSÕES}

\subsection{GRANULOMETRIA}

Os resultados da distribuição granulométrica mostraram que a dimensão máxima característica do material é de $19 \mathrm{~mm}$, valor justificado pelo processo de trituração do material. O módulo de finura médio encontrado dos resíduos de porcelana foi de 4,61, sendo classificado como areia grossa (M. F. > 3,9) (Petrucci, 1970). No ensaio de peneiramento, o material passante na peneira de abertura 0,075 $\mathrm{mm}$ (material pulverulento) foi de $4 \%$, indicando que a adição possui uma quantidade relevante (eficaz) de finos, principalmente, devido ao seu processo de moagem. Cabe ressaltar que o maior percentual de material passante foi observado na peneira de malha no 3/4 - abertura de $19 \mathrm{~mm}$ $(97,91 \%)$.

\subsection{TEOR DE ABSORÇÃO DOS AGREGADOS}

A absorção de água é uma propriedade diretamente relacionada com a porosidade do material, como também é influenciada pelo tipo e forma de obtenção destes agregados. Os resultados do teor de absorção dos materiais são apresentados na Tabela 1, média dos ensaios de três amostras para o agregado miúdo e AIP, somente o agregado graúdo possui valores de duas amostras oriundos da pesquisa de Souza e Bernardo (2014).

Verifica-se que a AIP obteve absorção média de $0,56 \%$, enquanto que a areia obteve

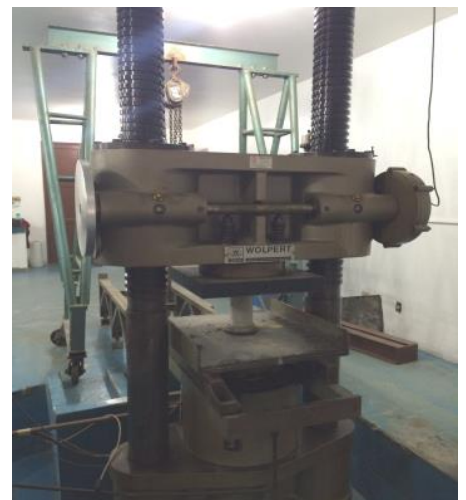

FIGURA 5: Ensaio de resistência à compressão axial da amostra referente à $50 \%$ de AIP aos 28 dias. FONTE: Autoria própria.

0,34\%. Fazendo uma comparação entre o resíduo e a areia, observa-se que o resíduo não apresentou uma elevada absorção, não necessitando de aditivo para plasticidade. A absorção do agregado graúdo foi de 0,65\%, conforme já observado em outros seixos (Souza e Barros, 2015).

Os valores encontrados concordam com a observação feita por Campos (2011) a respeito dos baixos índices de absorção de água do resíduo de porcelana. Esta menor capacidade de absorção resultou em traços de concreto com valores satisfatórios de abatimento de tronco de cone.

\subsection{MASSA ESPECÍFICA DOS AGREGADOS}

Conforme preconiza a NM 52 (ABNT, 2009), foram obtidos os resultados da massa específica dos insumos, apresentados na Tabela 2.

Os resultados demonstraram que a massa específica da AIP foi menor em relação às naturais. Verificou-se que esta situação é comumente encontrada, sendo justificada pela porosidade das partículas dos materiais cerâmicos (Souza e Bernardo, 2014). Os dados deste ensaio foram importantes para calcular o consumo de materiais utilizados na produção das misturas.

\subsection{ABATIMENTO DO TRONCO DE CONE (SLUMP TEST)}

O ensaio de abatimento de tronco de cone foi realizado para cada traço, ou seja, de referência e das adições de $25 \%$ e $50 \%$ da AIP, conforme NBR NM 67 (ABNT, 1998). Os valores encontrados podem ser observados na Figura 6. 
TABELA 1: Absorção do agregado miúdo, agregado graúdo e da AIP.

\begin{tabular}{lcccc}
\multicolumn{1}{c}{ Descrição } & Amostra 01 & Amostra 02 & Amostra 03 & Média \\
\hline Absorção do agregado miúdo (\%) & 0,34 & 0,34 & 0,35 & 0,34 \\
\hline Absorção do agregado graúdo (\%) & 0,71 & 0,59 & - & 0,65 \\
\hline Absorção do resíduo de porcelana - AIP (\%) & 0,56 & 0,59 & 0,54 & 0,56 \\
\hline
\end{tabular}

FONTE: Autoria Própria.

\begin{tabular}{lccc}
\hline \multicolumn{2}{c}{ TABELA 2: Média da massa específica do agregado miúdo, graúdo e resíduo (AIP). } \\
\hline \multicolumn{1}{c}{ Descrição } & Areia & Seixo & AIP \\
\hline $\begin{array}{l}\text { Massa específica aparente do agregado seco } \\
-\mathbf{d}_{\mathbf{1}}\left(\mathrm{g} / \mathrm{cm}^{\mathbf{3}}\right)\end{array}$ & 2,63 & 2,64 & 2,3 \\
\hline $\begin{array}{l}\text { Massa específica do agregado saturado } \\
\text { superfície seca (SSS) }-\mathbf{d}_{\mathbf{2}}\left(\mathrm{g} / \mathrm{cm}^{\mathbf{3}}\right)\end{array}$ & 2,63 & 2,61 & 2,31 \\
\hline \begin{tabular}{l} 
Massa específica do agregado $-\mathbf{d}_{\mathbf{3}}\left(\mathrm{g} / \mathrm{cm}^{\mathbf{3}}\right)$ \\
\hline
\end{tabular} & 2,64 & 2,59 & 2,33 \\
\hline
\end{tabular}

FONTE: Autoria Própria.

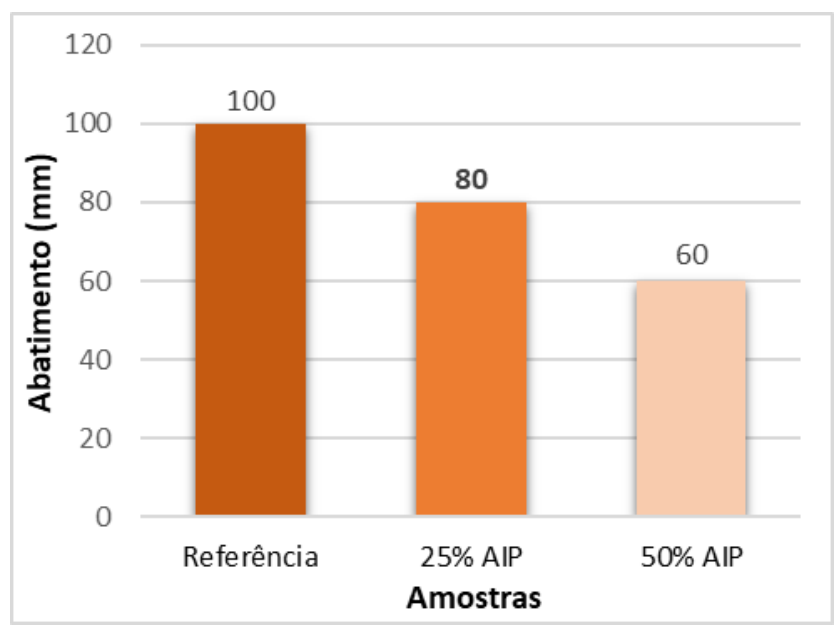

FIGURA 6: Resultados referentes ao ensaio de abatimento do tronco de cone - Slump Test.

FONTE: Autoria própria.

Observou-se então que à medida que se aumenta o percentual de substituição do agregado por resíduo, ocorreu a redução do abatimento, ou seja, o concreto ficava mais consistente. Este comportamento é justificado pela maior capacidade de absorção de água do resíduo, 35\% maior comparado a areia.

\subsection{ABSORÇÃO DE ÁGUA DOS CORPOS DE PROVA E ÍNDICES DE VAZIOS POR IMERSÃO}

Os valores obtidos nos ensaios de absorção de água por imersão e índices de vazios realizados no final do processo de cura aos 28 dias, para cada teor de substituição estudado, foram determinados de acordo com os procedimentos da NBR 9778 (ABNT, 2005) e estão apresentados na Tabela 3. 
TABELA 3: Resultado do ensaio de absorção de água por imersão e índices de vazios.

\begin{tabular}{|c|c|c|c|c|c|c|}
\hline \multirow{2}{*}{ Descrição } & \multicolumn{2}{|c|}{ Referência } & \multicolumn{2}{|c|}{$25 \%$ AIP } & \multicolumn{2}{|c|}{$50 \%$ AIP } \\
\hline & $C P-01$ & $\mathrm{CP}-02$ & $\mathrm{CP}-03$ & $C P-04$ & $C P-05$ & $\mathrm{CP}-06$ \\
\hline $\begin{array}{l}\text { Absorção de água por } \\
\text { imersão (\%) }\end{array}$ & 4,39 & 4,94 & 4,94 & 4,65 & 5,13 & 5,71 \\
\hline $\begin{array}{l}\text { Média da absorção de } \\
\text { água por imersão (\%) }\end{array}$ & \multicolumn{2}{|c|}{4,67} & \multicolumn{2}{|c|}{4,80} & \multicolumn{2}{|c|}{5,15} \\
\hline Índice de vazios (\%) & 9,87 & 11,00 & 10,95 & 10,33 & 11,29 & 11,28 \\
\hline $\begin{array}{l}\text { Média do índice de vazios } \\
\text { (\%) }\end{array}$ & \multicolumn{2}{|c|}{10,44} & \multicolumn{2}{|c|}{10,64} & \multicolumn{2}{|c|}{11,28} \\
\hline
\end{tabular}

Analisando os resultados das médias obtidas nos ensaios físicos, verifica-se que quanto maior o índice de vazios existente no concreto, maior foi à absorção de água por imersão dos mesmos. O concreto é um material que, devido sua constituição porosa, não é capaz de preencher por si só, a totalidade dos vazios do agregado da pasta de cimento. Com isso, a interconexão entre os vazios (ou poros) no concreto torna-o permeável à água (NEVILLE e BROOKS, 2013). Dessa forma, um percentual elevado de absorção e índice de vazios pode corroborar com a diminuição da durabilidade das peças de concreto e queda dos valores de resistência.

\subsection{RESISTÊNCIA À COMPRESSÃO}

$\mathrm{Na}$ Tabela 4 estão apresentados os resultados de resistência à compressão dos corpos de prova aos 07 e 28 dias (amostras e médias).

Conforme esperado, os valores encontrados para as resistências aos 28 dias foram maiores em relação aos 7 dias, devido ao processo de hidratação do cimento. A Figura 7 resume a resistência dos traços em estudo aos 7 e 28 dias. Analisando os resultados, percebe-se que houve um aumento de aproximadamente $10,6 \%$ ao correlacionar o traço de referência nas idades de 7 e 28 dias. Com teor de substituição de $25 \%$, o acréscimo de resistência foi de $19,7 \%$ em relação às misturas com mesmas idades e para as misturas contendo $50 \%$ de substituição o aumento chegou a $26,87 \%$. Dessa forma, ocorreu uma melhora contínua da resistência conforme a idade e o teor de porcelana adicionado, justificando a atividade pozolânica presente nesse resíduo (CAMPOS, 2011).

TABELA 4: Resultados referentes à resistência à compressão dos corpos de prova ensaiados.

\begin{tabular}{lcccccc}
\multirow{2}{*}{ Amostras } & \multicolumn{2}{c}{ Referência } & \multicolumn{2}{c}{$\mathbf{2 5 \%}$ AIP } & \multicolumn{2}{c}{$\mathbf{5 0 \%}$ AIP } \\
\cline { 2 - 7 } & $\mathbf{7}$ dias & $\mathbf{2 8}$ dias & $\mathbf{7}$ dias & $\mathbf{2 8}$ dias & $\mathbf{7}$ dias & $\mathbf{2 8}$ dias \\
\hline $\mathbf{C P}-\mathbf{0 1}$ & 16,78 & 22,81 & 13,77 & 18,00 & 15,34 & 26,30 \\
\hline $\mathbf{C P}-\mathbf{0 2}$ & 19,15 & 17,05 & 13,89 & 20,15 & 15,57 & 18,67 \\
\hline $\mathbf{C P}-\mathbf{0 3}$ & 18,44 & 20,98 & 17,08 & 17,55 & 16,58 & 19,97 \\
\hline Média & 18,12 & 20,28 & 14,91 & 18,57 & 15,83 & 21,65 \\
\hline Desvio padrão & 1,213 & 2,944 & 1,878 & 1,391 & 0,659 & 4,078 \\
\hline
\end{tabular}




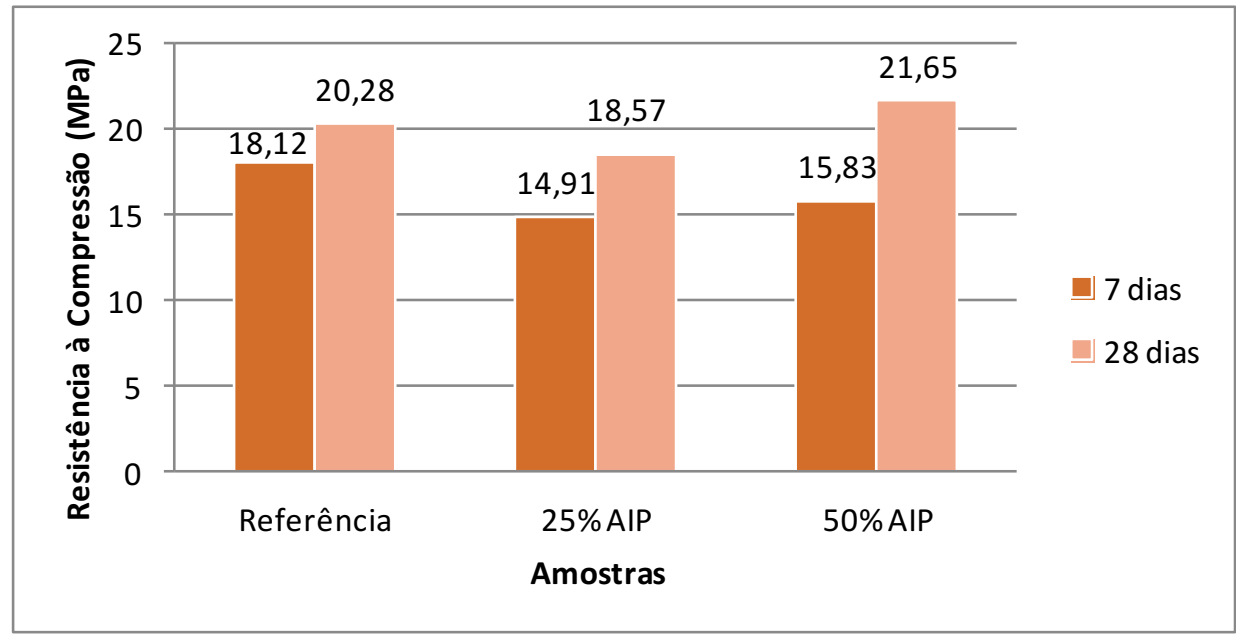

FIGURA 7: Resultados referentes à média das resistências à compressão das amostras.

FONTE: Autoria própria.

Entretanto, quando comparado com o traço de referência, as misturas com idade de 28 dias e com substituição de $50 \%$ de resíduo a média das resistências foram superiores. Comparando também à resistência a compressão do traço com $50 \%$ de AIP com a resistência média dos corpos de prova de referência aos 28 dias, percebe-se que o aumento não foi tão expressivo, apenas $6 \%$. Realizando o mesmo comparativo com o traço de $25 \%$ de AIP, observa-se que este apresentou um valor $8 \%$ inferior ao traço de referência. Analisando a pesquisa de Campos (2011), tal situação não era esperada, almejava que todos os traços contendo porcelana apresentassem valores de tensão maiores que o de referência. A baixa resistência dos corpos de provas também estão associados a fragilidade do seixo da região, em que nos ensaios de resistência à compressão os seixos se fragmentaram em todas as rupturas, como pode ser observado nas Figuras 8 e 9 .

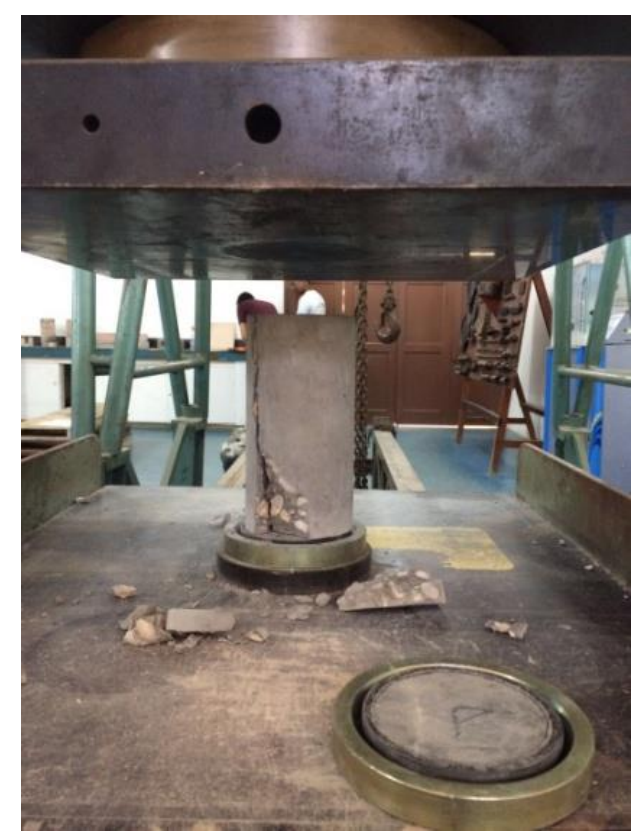

FIGURA 8: Ensaio de resistência à compressão com detalhe na fragmentação do seixo na amostra. FONTE: Autoria própria. 


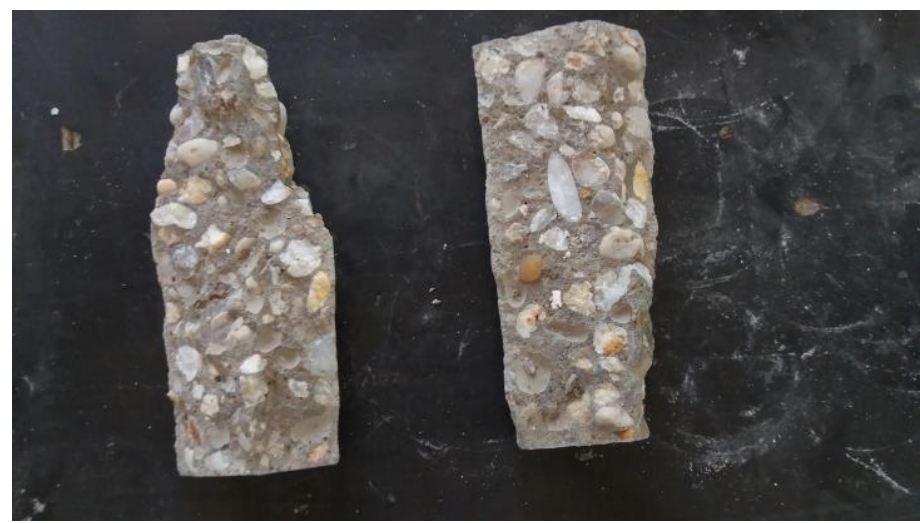

FIGURA 9: Amostra após ensaio de resistência à compressão - detalhe do comportamento do seixo.

FONTE: Autoria própria.

\subsection{RESISTÊNCIA À TRAÇÃO POR COMPRESSÃO DIAMETRAL}

Os resultados dos ensaios de resistência à tração por compressão diametral para todos os traços em análises aos 28 dias são apresentados na Figura 10.

Observa-se o traço com $25 \%$ de AIP, conferiu uma boa resistência ao concreto nessa propriedade. No entanto, a resistência à tração por compressão diametral obteve menor intensidade quando em relação ao ensaio de compressão axial obtido nesta pesquisa.

\section{CONCLUSÕES}

A aplicação de resíduos de isoladores elétricos de porcelana para o traço em estudo indicou um bom potencial de utilização deste deste material, uma vez que apresentou baixa absorção de água e aumento considerável da resistência a compressão com substituição tanto de $25 \%$ quanto de $50 \%$ de AIP entre as idades de 7 e 28 dias. Ressalta-se a melhora atingida pelo traço com substituição de $25 \%$ AIP do agregado miúdo na resistência à tração por compressão diametral. Vislumbrando a adequação dos processos de construção civil (em todas as etapas) nos requisitos de sustentabilidade, este resíduo possui grande potencial na substituição de agregados na mistura e, com base em futuras pesquisas, busca a validação deste material em diversos requisitos como, por exemplo, índice de pozolanicidade, durabilidade do compósito e variação da composição química. Portanto, com base neste trabalho e metodologia utilizada, isoladores elétricos de porcelana contribuíram para melhoria nas propriedades mecânicas do concreto.

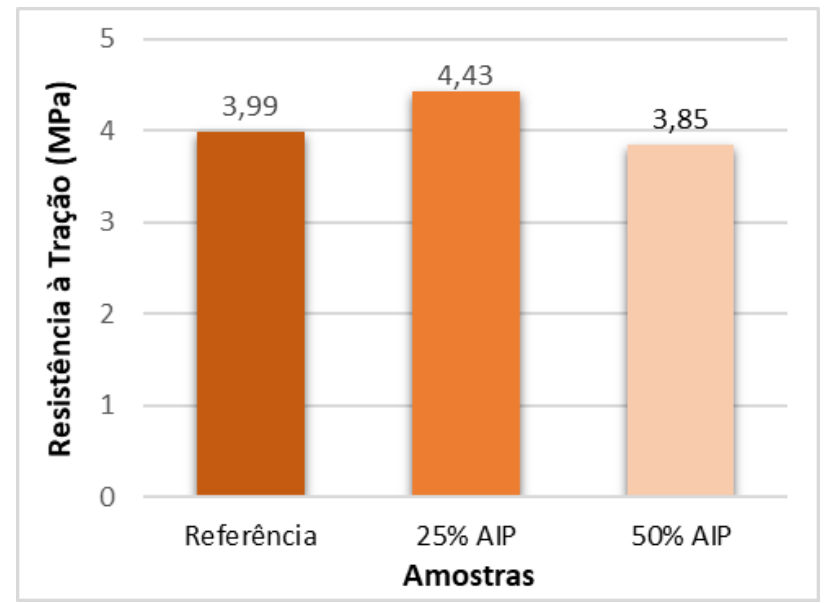

FIGURA 10: Resistência à tração por compressão diametral (média).

FONTE: Autoria própria. 


\section{AGRADECIMENTOS}

Agradecimentos à empresa Dow Corning Silício localizada no estado do Pará por fornecer os isoladores elétricos de porcelana e a Universidade Federal do Pará (UFPA) por disponibilizar seus laboratórios para execução desta pesquisa.

\section{REFERÊNCIAS BIBLIOGRÁFICAS}

ASSOCIAÇÃO BRASILEIRA DE NORMAS TÉCNICAS. NBR 5738: Concreto - Procedimentos para moldagem e cura de corpos-de-prova. Rio de Janeiro, 2015.

NBR 6118: Projeto de estruturas de concreto - Procedimento. Rio de Janeiro. 2014.

NBR 9778: Argamassa e concreto endurecidos - Determinação da absorção de água por imersão - Índice de vazios e massa específica. Rio de Janeiro, 2005.

NBR NM 248: Agregados Determinação da composição granulométrica. Rio de Janeiro, 2003.

NBR NM 30: Agregado miúdo Determinação da absorção de água. Rio de Janeiro, 2001.

- NBR NM 52: Agregado Miúdo Determinação de massa especifica e massa específica aparente. Rio de Janeiro, 2009.

NBR NM 67: Determinação da consistência pelo abatimento do tronco de cone. Brasil, 1998.

CAMPOS, M. A. Análise microestrutural e das propriedades mecânicas e de durabilidade de argamassas e concretos com Isoladores elétricos de porcelana. Tese (Doutorado) - Universidade Estadual de Campinas - Unicamp. Faculdade de Engenharia Civil, Arquitetura e Urbanismo. Campinas-SP, 2011.

CAMPOS, M. A. Estudo do reaproveitamento de isoladores elétricos de porcelana como agregados em argamassas e concretos. Dissertação (Mestrado) Universidade Estadual de Campinas - Unicamp. Faculdade de Engenharia Civil, Arquitetura e Urbanismo. Campinas-SP, 2009.

CAMPOS, M. A.; PAULON, V. A. Utilização de agregados alternativos de isoladores elétricos de porcelana em concretos. Concreto y Cemento. Investigación y Desarrollo, Vol. 7 Núm. 1, de La pág. 30 a La 43, Júlio Diciembre. 2015.
CONAMA, MINISTÉRIO DO MEIO AMBIENTE, CONSELHO NACIONAL DO MEIO AMBIENTE - CONAMA. Resolução $\mathrm{n}^{\circ}$ 307, de 05 de julho de 2002. Estabelece diretrizes, critérios e procedimentos para a gestão dos resíduos da construção civil. Diário Oficial da República Federativa do Brasil, Brasília, DF, n 136, 17 de julho de 2002. Seção 1, p. 95-96.

FRANCK, R.; JOUKOSKI, A.; PORTELLA, K. F.; BERKSEN, R. Utilização de rejeitos de isoladores de porcelana em concretos, em substituição parcial ou total dos agregados naturais. In: CONGRESSO BRASILEIRO DO CONCRETO, 2004, Florianópolis. Anais Florianópolis: IBRACON, 2004.

ISOLADORES SANTANA. Porcelana - Isoladores: Processo de Fabricação. Disponível: <http://www.isantana.com.br>. Acesso em: 30/05/2017.

JUAN, A.; MEDINA, C.; GUERRA, M. I.; MORÁN, J. M.; AGUADO, P. J.; ROJAS, M. I. S. de; FRÍAS, M.; RODRÍGUEZ, O. Re-use of ceramic wastes in construction. In: Ceramic Materials, 2010. Disponível em:

<http://cdn.intechopen.com/pdfs/11637/InTechRe_use _of_ceramic_wastes_in_construction.pdf $>$.

NEVILLE, A. M.; BROOKS, J. J. Tecnologia do concreto. Tradução Ruy Alberto Cremonini. 2a Ed. Porto Alegre, Bookman. 2013.

PETRUCCI, E.G. Concreto de cimento Portland. 2. Ed. Porto Alegre, Editora Globo. 1970.

PORTELLA, K. F.; JOUKOSKI, A.; FRANCK, R.; DERKSEN, R. Reciclagem secundária de rejeitos de porcelanas elétricas em estruturas de concreto: determinação do desempenho sob envelhecimento acelerado. Cerâmica 52. 155-167. 2006).

SOUZA, F.J.P; NEVES, W.F.; ALARCON, O.E. Estudo da viabilidade de obtenção de isoladores elétricos a partir de resíduo de esmaltação. Set 2004, vol. 50, no. 315 São Paulo. ISSN 0366-6913.

SOUZA, G. T; BERNARDO, K. S. M. Confecção de argamassa com a substituição total do agregado natural por agregados provenientes de resíduo de construção e demolição (RCD). Monografia (Graduação) - Universidade Federal do Pará- UFPA. Faculdade de Engenharia Civil, Tucuruí-PA, 2014.

SOUZA, L. C; BARROS, M.R. Estudo do aproveitamento do resíduo industrial obtido na produção do silício metálico/ empresa Dow Corning Silício do Brasil em concretos bombeados. Monografia (Graduação) Universidade Federal do Pará- UFPA. Faculdade de Engenharia Civil, Tucuruí-PA, 2015. 